\title{
Update on subcutaneous methotrexate for inflammatory arthritis and psoriasis
}

This article was published in the following Dove Press journal:

Therapeutics and Clinical Risk Management

\author{
Gino Antonio Vena ${ }^{1,2}$ \\ Nicoletta Cassano ${ }^{1,2}$ \\ Florenzo lannone ${ }^{3}$ \\ 'Dermatology and Venereology Private \\ Practice, Bari, ${ }^{2}$ Dermatology and \\ Venereology Private Practice, Barletta, \\ ${ }^{3}$ Department of Emergency and Organ \\ Transplantation, Rheumatology Unit, \\ University of Bari, Bari, Italy
}

\begin{abstract}
Methotrexate (MTX) is one of the mainstays of treatment for several immune-mediated inflammatory joint and skin diseases, especially rheumatoid arthritis (RA) and moderate-tosevere psoriasis. Oral MTX has been used for the treatment of such diseases for decades for many reasons. There is, however, a relevant interpatient variability of clinical and safety outcomes that can also be related to differences in patients' individual pharmacogenomic profile. Orally administered MTX has been found to have a saturable intestinal absorption and nonlinear pharmacokinetics, with significant consequences on drug bioavailability and clinical efficacy. The current evidence shows that parenterally administered MTX results in rapid and complete absorption, higher serum levels, and less variable exposure than oral dosing. The use of parenteral MTX, particularly when administered as a subcutaneous (SC) injection, has recently raised great interest in order to overcome the limitations of oral MTX. The effectiveness and safety of SC MTX have mostly been assessed in rheumatological settings, especially in patients with RA. There are only a limited number of data on SC MTX in juvenile idiopathic arthritis and even fewer in psoriatic disease. Various clinical experiences have suggested that SC MTX is more effective than oral MTX and may provide significant benefit even in patients in whom oral MTX proved to be inadequate. The increased efficacy of SC MTX resulting from higher drug exposure compared with oral MTX has been associated with a similar safety profile and in various reports even with a lower frequency of gastrointestinal complaints. The aim of this article was to review the available literature data on SC MTX treatment of inflammatory arthritis, with special emphasis on RA and psoriasis, examining differences with oral MTX treatment. A brief mention of pharmacokinetics, pharmacodynamic features and pharmacoeconomic considerations is also given.
\end{abstract}

Keywords: subcutaneous methotrexate, efficacy, tolerability, juvenile idiopathic arthritis, rheumatoid arthritis, psoriatic disease

\section{Introduction}

Methotrexate (MTX), a folic acid reductase inhibitor, is one of the mainstays of treatment for many immune-mediated joint and skin disorders, especially moderateto-severe psoriasis and rheumatoid arthritis (RA).

MTX is the most common disease-modifying antirheumatic drug (DMARD) employed in daily practice to treat inflammatory arthritis and remains the cornerstone of RA treatment, being capable of decreasing disease activity and radiological progression in a proportion of patients. It is established that prompt diagnosis and a treat-to-target approach can increase the likelihood of inducing sustained remission or low disease activity in active RA. In some patients, this goal can be achieved using MTX as monotherapy or in combination with other traditional DMARDs. The updated recommendations by the European League Against Rheumatism (EULAR) have
Correspondence: Gino Antonio Vena Dermatology and Venereology Private Practice, Via Fanelli, 206/I6, 70I25,

Bari, Italy

Tel +390805025794

$\mathrm{Fax}+390803943363$

Email ginovena@gmail.com BY $\mathrm{NC}$ and incorporate the Creative Commons Attribution - Non Commercial (unported, v3.0) License (http://creativecommons.org/licenses/by-nc/3.0/). By accessing the work you
hereby accept the Terms. Non-commercial uses of the work are permitted without any further permission from Dove Medical Press Limited, provided the work is properly attributed. For permission for commercial use of this work, please see paragraphs 4.2 and 5 of our Terms (https://www.dovepress.com/terms.php). 
corroborated the role of MTX in the therapeutic management of RA defining this drug as an important part of the first-line strategy and the anchor drug in combination therapy with most biological DMARDs. ${ }^{1}$

MTX has traditionally been believed to be less efficacious in psoriatic arthritis (PsA) than RA. In accordance with some authors, ${ }^{2}$ MTX efficacy may be underrated in PsA owing to the same historical problems encountered in the interpretation of the evidence in RA that are possibly related to the intrinsic and pragmatic limitations of clinical trials rather than to true limitations of MTX effectiveness.

Various clinical trials have investigated the efficacy of MTX in psoriasis, and different MTX-based regimens have been shown to improve the Psoriasis Area and Severity Index (PASI) of at least $75 \%$ (PASI75) in up to $40 \%$ of patients by week $24 .{ }^{3}$ A systematic review summarized the realworld evidence on effectiveness of systemic therapies for the treatment of plaque psoriasis in adults. ${ }^{4}$ In retrospective analysis depicting the real-life setting, treatment with MTX 10-20 mg weekly was found to induce a PASI75 response in $40 \%-49 \%$ of patients at week $12,62 \%$ at week 24 , and up to $81 \%$ at 1 year. Unfortunately, data from prospective studies are lacking.

Oral MTX has been used in the field of rheumatology and dermatology for decades for several reasons, including efficacy, easy intake, and low cost. However, some patients may require higher doses of oral MTX within the therapeutic range that can be poorly tolerated. It is well known that there is a considerable interpatient variability of clinical and safety outcomes during treatment of various chronic inflammatory diseases with low-dose MTX, which can also be due to differences in patients' individual pharmacogenomic profile involving drug transport, metabolism, and pharmacodynamic pathways. $^{5,6}$

These premises have led to scrutiny of the feasibility of parenteral MTX in order to overcome the limitations of oral MTX. ${ }^{7}$ As a result, the use of parenteral MTX, particularly when given as a subcutaneous (SC) injection, has raised great interest in recent years. The effectiveness and safety of SC MTX have mostly been assessed in rheumatological settings but there are only limited data on psoriasis.

The aim of this manuscript was to review the current evidence on SC MTX treatment of inflammatory arthritis, with special emphasis on RA and psoriasis, examining differences with oral MTX treatment.

\section{Methods of article search and selection}

We searched the PubMed database (from January 1, 1990 up to August 31, 2017), using the term "subcutaneous methotrexate" in combination with other pertinent keywords (mainly corresponding to the diseases analyzed), to identify relevant reports, including clinical trials and reviews. Only articles written in English were chosen. They were selected after reading the title and abstract and then the full text was read to evaluate their content. Furthermore, we manually searched articles from the references cited in the retrieved articles. Our objective was to collect a comprehensive number of publications regarding various aspects of SC MTX treatment (eg, pharmacokinetics, pharmacodynamic peculiarities, efficacy, tolerability, and pharmacoeconomic issues). We performed a narrative review instead of a proper meta-analysis in the light of the heterogeneity of data shown by the publications examined (eg, study design, patient populations, drug dosing, study duration, and outcomes).

Clinical data included in this review deal with RA, juvenile idiopathic arthritis (JIA), and psoriatic disease, which are the approved indications for MTX among rheumatic and skin diseases. As most of such reports refer to RA, the selection of articles regarding SC MTX use in RA patients was focused on studies that compared oral and SC formulations or assessed the effect of switching from oral MTX to SC MTX. Information on bioavailability of SC MTX in comparison with the oral route was instead obtained from studies performed in different test subjects, including patients with Crohn's disease and healthy subjects.

\section{Bioavailability and pharmacokinetics of SC MTX formulation}

Orally administered MTX has been found to have a saturable intestinal absorption and nonlinear pharmacokinetics. ${ }^{8,9}$ These features may have a relevant impact on drug bioavailability and clinical efficacy.

The current evidence shows that parenterally administered MTX results in rapid and complete absorption, higher serum levels, and less variable exposure than oral dosing. No statistically significant differences of the relative bioavailability between SC and intramuscular administration of MTX were detected in six patients with RA. ${ }^{10}$ Similarly, the equivalence of SC and intramuscular dosing was previously demonstrated in five patients with RA, treated with MTX 12.5-25 mg weekly, who received two treatments at the same dose, 1 week apart, given in a randomly assigned order. In particular, there were no differences in pharmacokinetic parameters (peak concentration, time to reach peak concentration, and area under the time vs concentration curve) for intramuscular and SC injections. ${ }^{11}$ Given the bioequivalence of the two formulations, the SC route has, therefore, been considered a more convenient and less painful way of administering low-dose MTX. ${ }^{11}$ 
Various pharmacokinetic studies (Table 1) consistently demonstrated that SC administration of MTX results in a significantly higher drug bioavailability as compared with the oral route. ${ }^{10,12-17}$ A meta-analysis has pointed out that, compared with oral administration, treatment of RA with SC MTX is significantly associated with increase in the area under plasma concentration curve from administration to last observed concentration at time $t$ and reduction in the time to reach maximum observed concentration without significant differences in maximum plasma concentration. ${ }^{18}$

Bioavailability of MTX given orally at stable doses of $25 \mathrm{mg} /$ week or more in adults with RA was found to be highly variable and significantly lower than detected with SC MTX, corresponding to approximately two-thirds of that of the $\mathrm{SC}$ administration. ${ }^{12}$

A more recent open-label multicenter study recruited RA patients who were treated with different doses of MTX within the therapeutic range used in rheumatology practice $(10-25 \mathrm{mg})$ and found that systemic exposure of oral MTX plateaued at doses $\geq 15 \mathrm{mg} /$ week. $^{13}$ In contrast, SC MTX showed a linear dose-proportional increase in systemic exposure that was greater than oral MTX at each dose and did not plateau over the doses investigated.

Different sites of SC administration (thigh and abdomen) resulted in bioequivalent drug exposure..$^{13}$

Taking into account that $\mathrm{SC}$ administration provides dose-proportional and higher drug exposure compared with oral MTX, successful dose-conversion strategies are needed, and a useful method with a convenient dose-conversion table has recently been proposed..$^{19}$ However, it is generally recommended that patients should receive the same dose of MTX used for oral administration when switching to SC MTX treatment. ${ }^{8}$

A pilot pharmacokinetic study in only six patients with chronic plaque psoriasis treated with SC or oral MTX (7.5 or $15 \mathrm{mg} /$ week) using dermal microdialysis demonstrated that drug levels and bioavailability of MTX were consistently higher in lesional skin than unaffected skin, without, however, finding a relation with the dose or the route of administration..$^{20}$

\section{Mechanism of action and correlation with the administration route}

MTX acts through competitive inhibition of the enzyme dihydrofolate reductase, thus inhibiting purine and thymidine nucleotide synthesis and decreasing the production of DNA and RNA. The anti-inflammatory effects are thought to result from further mechanisms, including modification in cellular redox state, inhibition of polyamines, and accumulation of anti-inflammatory substances, such as adenosine the release of which into the extracellular space is stimulated by MTX. ${ }^{21}$

After MTX enters the cell, there is an enzymatic addition of at least one glutamate residue to the MTX molecule. This process, known as polyglutamation, appears to be relevant for promoting drug intracellular retention and pharmacologic activity, and, in fact, MTX polyglutamate metabolites are

Table I Bioavailability of oral MTX compared with SC MTX

\begin{tabular}{|c|c|c|c|}
\hline References & Sample & MTX weekly dose & Relevant results \\
\hline 10 & 12 patients with RA & $7.5-17.5 \mathrm{mg}$ & $\begin{array}{l}\text { Mean relative bioavailability of SC MTX was } \\
\text { significantly higher than oral MTX ( } 0.97 \text { vs } 0.85)\end{array}$ \\
\hline 12 & I5 patients with RA & 25-40 mg (median, $30 \mathrm{mg}$ ) & $\begin{array}{l}\text { Mean bioavailability of oral MTX was significantly } \\
\text { lower }(0.64 \text {, range } 0.21-0.96) \text { compared with SC MTX }\end{array}$ \\
\hline 13 & $\begin{array}{l}49 \text { RA patients enrolled in an } 8 \text {-week, } \\
\text { open-label, randomized-sequence, } \\
\text { three-way crossover trial ( } 47 \text { completed } \\
\text { the study) }\end{array}$ & $\begin{array}{l}10,15,20 \text {, and } 25 \mathrm{mg} \text { in a } \\
\text { random sequence of three } \\
\text { treatments: oral, SC into the } \\
\text { abdomen, and SC into the thigh }\end{array}$ & $\begin{array}{l}\text { Greater systemic bioavailability of SC MTX at all dose } \\
\text { levels (relative bioavailability at I0, I5, 20, and } 25 \mathrm{mg} \\
\text { was } 121 \%, \mathrm{I} 14 \%, 131 \% \text {, and } 141 \% \text {, respectively, of that } \\
\text { seen with oral MTX) }\end{array}$ \\
\hline 14 & I7 patients with JIA & $\begin{array}{l}\text { 6. I-22.5 mg/m² for oral MTX; } \\
8.8-28.6 \mathrm{mg} / \mathrm{m}^{2} \text { for SC MTX }\end{array}$ & $\begin{array}{l}\text { Nonlinear pharmacokinetics of oral MTX. } \\
\text { In four patients switched from oral to SC MTX at } \\
\text { the same dose, the bioavailability of oral MTX was } \\
\text { I I\%-I5\% lower as compared with SC MTX }\end{array}$ \\
\hline 15 & $\begin{array}{l}62 \text { healthy subjects recruited in an } \\
\text { open-label, randomized, two-sequence, } \\
\text { two-period, single-dose, crossover study }\end{array}$ & $\begin{array}{l}\text { Four dose groups }(7.5,15 \text {, } \\
22.5 \text {, and } 30 \mathrm{mg})\end{array}$ & $\begin{array}{l}\text { Bioavailability was generally higher with SC MTX } \\
\text { (injected by prefilled autoinjector pen) compared with } \\
\text { oral MTX for all dose groups (higher } C_{\max } \text { and } \text { AUC }_{0-t} \\
\text { values obtained with SC MTX) }\end{array}$ \\
\hline 16 & $\begin{array}{l}\text { I0 patients with stable CD randomized } \\
\text { to receive their regular maintenance dose }\end{array}$ & $15-25 \mathrm{mg}$ for 3 weeks & $\begin{array}{l}\text { Bioavailability of oral MTX was highly variable and } \\
\text { averages } 73 \% \text { of that of SC MTX }\end{array}$ \\
\hline 17 & I I patients with CD & $25 \mathrm{mg}$ for 2 weeks & $\begin{array}{l}\text { Mean relative bioavailability of } 86 \%(62 \%-108 \%) \text { of } \\
\text { oral MTX compared with SC MTX }\end{array}$ \\
\hline
\end{tabular}

Abbreviations: AUC, area under the plasma-concentration curve; $C D$, Crohn's disease; $C_{\max }$, maximum plasma concentration; JIA, juvenile idiopathic arthritis; MTX, methotrexate; RA, rheumatoid arthritis; SC, subcutaneous. 
considered the long-lived active compounds. ${ }^{21}$ The longer chain polyglutamates $\left(\mathrm{MTXGlu}_{3+4+5}\right)$ have been reported to have the greatest inhibitory potency on the folate pathway enzymes responsible for the pharmacological activity of MTX. Hence, intracellular MTX polyglutamates have been proposed as a potential biomarker of efficacy and toxicity of MTX therapy for inflammatory arthropathies. ${ }^{22}$

In a pharmacokinetic evaluation of 10 RA patients, ${ }^{23} \mathrm{a}$ switch from oral to parenteral MTX was associated with a selective accumulation of long-chain MTX polyglutamates, consisting in a $37 \%$ increase in long-chain and a $132 \%$ increase in very long-chain polyglutamates, which was paralleled by a $31 \%$ reduction in disease activity.

After assessing red blood cell MTX polyglutamate concentrations in RA patients treated with oral MTX, switching to SC MTX in such patients caused an increase in long-chain polyglutamate levels, which, in turn, showed a significant correlation with decrease in disease activity. ${ }^{24}$

In a cohort of patients with JIA receiving diverse formulations of MTX, there was a great variability in concentrations of MTX polyglutamates, which appeared to be influenced by the route of MTX administration. ${ }^{25}$ The route of administration also contributed to the red blood cell concentrations of polyglutamate subtypes. In particular, long-chain polyglutamates (MTXGlu ${ }_{3-5}$ ), which were the subtypes best correlated with the total intracellular concentration, were more abundant in patients treated with SC MTX, whereas higher concentrations of short-chain MTXGlu ${ }_{1+2}$ were observed in patients receiving oral doses of MTX.

\section{Clinical trials in patients with RA and JIA}

The majority of findings regarding the effectiveness and tolerability of SC MTX stem from the assessment of adult patients with RA. Most of the available data suggest that SC MTX is significantly more effective than oral MTX at the same dosage in patients with active RA with no increase in side effects and even with better tolerability outcomes.

It should be emphasized that the study design of many studies precludes a direct comparison of both therapeutic efficacy and drug tolerance between oral and SC formulations.

A meta-analysis based on 7 studies involving 1,335 patients with RA highlighted the superior clinical efficacy of SC MTX over oral MTX, in terms of achievement of the American College of Rheumatology (ACR) criteria for $20 \%$ improvement (ACR20) (odds ratio [OR] 1.68; 95\% CI 1.09-2.61) and ACR criteria for 70\% improvement (ACR70; OR 1.52; 95\% CI 1.02-2.26), as well as relief of pain. ${ }^{18}$ No significant differences in the ACR criteria for 50\% improvement
(ACR50) rates were revealed between the two treatment groups. However, the risk of treatment failure was not decreased with SC MTX.

MTX has traditionally been described as a slow-acting drug, with recommendations to evaluate clinical response at least after 12 weeks. However, in the opinion of some researchers, ${ }^{26}$ the kinetics of treatment with parenteral MTX appears to be more rapid. Preliminary data showed a prompt effect of optimal initial dosing of SC MTX in patients with early RA, with significant improvement in multiple efficacy parameters seen by 6 weeks, including Clinical Disease Activity Index- and 28-joint Disease Activity Score (DAS28)-based remission. ${ }^{26}$

In light of the pharmacokinetic findings mentioned above, parenteral administration has been recommended when MTX doses $\geq 10-15 \mathrm{mg} / \mathrm{m}^{2}$ in children with JIA are required. ${ }^{14}$

Similarly, in RA patients, in addition to suggesting SC MTX therapy in case of inadequate response to oral MTX, the $\mathrm{SC}$ route might be considered in clinical practice also for doses $>15 \mathrm{mg} .{ }^{19}$

Efficacy and tolerability data from cohorts of patients with RA and JIA are summarized in the following sections, focusing the attention on results from comparative studies or change in administration route.

\section{Comparative studies with SC MTX vs oral MTX: efficacy data}

A limited number of trials have compared oral and SC formulations of MTX in patients with RA or JIA (Table 2), and most of them were open-label observational studies..$^{27-31}$

The study performed by Braun et al was the first, prospective, randomized, double-blind trial to specifically assess the efficacy outcomes achievable with MTX $15 \mathrm{mg} /$ week given orally or by SC injection in patients with active RA. ${ }^{27}$ The primary efficacy end point was the ACR20 at week 24. Patients who did not meet the ACR2 0 criteria at week 16 were switched from $15 \mathrm{mg}$ oral to SC MTX at the same dose, and from $15 \mathrm{mg}$ SC MTX to $20 \mathrm{mg}$ SC MTX for further 8 weeks. At week 16, 52 subjects were ACR20 nonresponders. SC MTX was found to be significantly more effective than oral administration of the same dosage. Statistically significant differences in the ACR20 and ACR70 response rates in favor of SC MTX were observed at week 24, whereas there was no difference in the proportion of patients achieving an ACR50 response. Patients with a disease duration $\geq 12$ months had even higher ACR20 response rates (89\% for SC MTX and 63\% for oral MTX).

These results were corroborated by subsequent prospective trials carried out in RA patients. ${ }^{28,29}$ 
Table 2 Comparison of efficacy results between oral MTX and SC MTX in patients with RA and JIA

\begin{tabular}{|c|c|c|c|}
\hline References & Study design and patients & Treatment & Efficacy results \\
\hline 27 & $\begin{array}{l}\text { Six-month, multicenter, randomized, } \\
\text { DB, double-dummy, controlled, } \\
\text { two-arm, Phase IV trial in } 384 \\
\text { MTX-naïve patients with active RA } \\
\text { (DAS28 } \geq 4 \text { ); } 375 \text { included in the } \\
\text { efficacy analysis }\end{array}$ & $\begin{array}{l}15 \mathrm{mg} / \text { week of oral MTX }(n=187) \text { or SC } \\
\text { MTX }(n=188) \text { for } 24 \text { weeks } \\
\text { At week } 16, \text { switch from I5 mg of oral } \\
\text { MTX to } 15 \mathrm{mg} \text { of SC MTX and from } 15 \mathrm{mg} \\
\text { of SC MTX to } 20 \mathrm{mg} \text { of SC MTX for } \\
8 \text { weeks in the absence of ACR } 20 \text { response }\end{array}$ & $\begin{array}{l}\text { At week } 24 \text {, significantly more patients treated } \\
\text { with SC MTX than with oral MTX showed } \\
\text { ACR20 ( } 78 \% \text { vs } 70 \% \text { ) and ACR70 ( } 41 \% \text { vs 33\%) } \\
\text { responses }\end{array}$ \\
\hline 28 & $\begin{array}{l}\text { Prospective study in } 92 \text { patients } \\
\text { with active RA }\end{array}$ & $\begin{array}{l}\text { Oral MTX }(n=46) \text { or SC MTX }(n=46) \text { at } \\
\text { equivalent dose for } 24 \text { weeks }\end{array}$ & $\begin{array}{l}\text { At } 24 \text { week, significant differences in favor of } \\
\text { SC MTX in ACR } 20 \text { and ACR } 50 \text { response rates } \\
\text { ( } 93 \% \text { vs } 80 \% \text {, and } 89 \% \text { vs } 72 \% \text {, respectively), } \\
\text { with similar ACR } 70 \text { response rates }\end{array}$ \\
\hline 29 & $\begin{array}{l}\text { Multicenter, prospective cohort study } \\
\text { to compare oral vs SC MTX over the } \\
\text { first year in } 666 \text { patients with early RA }\end{array}$ & $\begin{array}{l}\text { Mean weekly dose over first } 3 \text { months of } \\
\text { I7.2 mg for oral MTX }(n=417) \text { and } 22.3 \mathrm{mg} \\
\text { for SC MTX }(n=249)\end{array}$ & $\begin{array}{l}\text { SC MTX associated with a lower rate of } \\
\text { treatment failure (HR 0.55, 95\% Cl 0.39-0.79) } \\
\text { and lower mean DAS28 scores }\end{array}$ \\
\hline 30 & $\begin{array}{l}\text { Retrospective analysis in } 4 \text { II patients } \\
\text { with JIA using the German MTX } \\
\text { Registry }\end{array}$ & $\begin{array}{l}\text { Oral MTX }(n=259) \text { and SC MTX }(n=152) \\
\text { at a similar weekly dose }(0.4 \mathrm{mg} / \mathrm{kg} \text { vs } \\
0.42 \mathrm{mg} / \mathrm{kg})\end{array}$ & $\begin{array}{l}\text { Comparable response according to the } \\
\text { ACR Pediatric } 30 \text { criteria after } 6 \text { months } \\
\text { of treatment }(73 \% \text { vs } 72 \%)\end{array}$ \\
\hline 31 & $\begin{array}{l}\text { Prospective observational study } \\
\text { of } 55 \text { patients with JIA }\end{array}$ & $\begin{array}{l}\text { Initial median weekly dose of II.7 mg/m² } \\
\text { for oral MTX }(n=10) \text { and } 14.4 \mathrm{mg} / \mathrm{m}^{2} \text { for } \\
\text { SC MTX }(n=45)\end{array}$ & $\begin{array}{l}\text { No differences in either the rate or the extent } \\
\text { of therapeutic response between the two } \\
\text { routes }\end{array}$ \\
\hline
\end{tabular}

Abbreviations: ACR, American College of Rheumatology; ACR20, ACR criteria for 20\% improvement; ACR50, ACR criteria for 50\% improvement; ACR70, ACR criteria for 70\% improvement; DAS28, 28-joint Disease Activity Score; DB, double blind; HR, hazard ratio; JIA, juvenile idiopathic arthritis; MTX, methotrexate; RA, rheumatoid arthritis; SC, subcutaneous.

Hazlewood et al examined the effectiveness of starting with oral vs SC MTX over the first year in a cohort of 666 patients with early RA (defined by symptoms $\leq 1$ year). ${ }^{29}$ Patients who received SC MTX were prescribed a higher dose of MTX as compared with those treated with oral MTX (mean dose over first 3 months was 22.3 vs $17.2 \mathrm{mg} /$ week). At 1 year, treatment change was required in $49 \%$ of patients initially treated with SC MTX compared with $77 \%$ of those in whom MTX was given orally. After adjusting for potential confounders, SC MTX was associated with a lower rate of treatment failure (hazard ratio [HR] 0.55, 95\% CI 0.39-0.79), which in most cases was due to inefficacy. Nevertheless, the result might have been influenced by the higher starting dose used with SC MTX. No significant difference in sustained remission or Health Assessment Questionnaire-Disability Index (HAQ-DI) was instead identified.

However, SC MTX did not prove the superiority over oral MTX in terms of efficacy and tolerability in patients with JIA, as findings obtained in series of such patients were less favorable to SC MTX. In fact, the retrospective analysis performed by Klein et al showed a similar discontinuation rate with oral and SC MTX treatments. ${ }^{30}$ In the same way, Fráňová et al described their experience with initial treatment with SC or oral MTX in patients with JIA. ${ }^{31}$ More patients received SC MTX, as it was preferentially prescribed in the authors' own practice. Neither the rate nor the extent of therapeutic response was reported to be influenced by the route of MTX administration, although such findings were not detailed further in the paper.

\section{Switch from oral MTX to SC MTX: efficacy data}

Flaring of polyarthritis following substitution of oral for parenteral administration of the same dose of MTX has been reported. ${ }^{32}$

Various studies have assessed the response to MTX following a switch to SC treatment in RA or JIA patients with inadequate response to oral MTX (Table 3). ${ }^{33-40}$ These studies were generally retrospective analyses.

An example involving RA patients was the so-called MENTOR study, an observational, retrospective study carried out at the Norfolk and Norwich University Hospital, UK. ${ }^{33}$ High continuation rates were seen in patients on SC MTX treatment, leading to a limited requirement of alternative therapeutic strategies including biologic therapy. Only $11.7 \%$ of patients previously treated with oral MTX discontinued therapy with SC MTX for any reason during the first year. Data extrapolated from the 2-year cohort indicated that, among patients switched from oral MTX because of inefficacy, only $13.7 \%$ failed also with SC MTX and in 11\% the addition of biologics was necessary.

In their cohort of RA patients, Mainman et al noted that a high proportion of the patients switching to SC therapy had extreme values of body mass index and many suffered from 
Table 3 Summary of efficacy results in series of patients with RA and JIA who were changed from oral to SC MTX

\begin{tabular}{|c|c|c|c|c|c|}
\hline \multirow[t]{2}{*}{ References } & \multirow[t]{2}{*}{$\begin{array}{l}\text { Study details and patients } \\
\text { switched }\end{array}$} & \multirow[t]{2}{*}{$\begin{array}{l}\text { Reasons for oral } \\
\text { MTX failure }\end{array}$} & \multicolumn{2}{|c|}{$\begin{array}{l}\text { Mean weekly MTX } \\
\text { dose }(\mathrm{mg})\end{array}$} & \multirow[t]{2}{*}{ Relevant results obtained with SC MTX } \\
\hline & & & Oral & SC & \\
\hline 33 & $\begin{array}{l}\text { Retrospective study of I96 RA } \\
\text { patients }\end{array}$ & $\begin{array}{l}\text { Inefficacy }(50.5 \%) \\
\text { AEs }(43.9 \%) \text {, other/ } \\
\text { unknown (5.6\%) }\end{array}$ & 17.7 & 16.3 & $\begin{array}{l}\text { Persistence of SC MTX therapy in } 83 \% \text { of } \\
\text { patients at I year, } 75.2 \% \text { at } 2 \text { years, and } 47.0 \% \\
\text { at } 5 \text { years }\end{array}$ \\
\hline 34 & $\begin{array}{l}\text { Post hoc analysis of } 57 \text { patients } \\
\text { from the prospective, open-label } \\
\text { CAMERA study }\end{array}$ & $\begin{array}{l}\text { AEs }(n=2 I) \text {, poor } \\
\text { efficacy }(n=36)\end{array}$ & $28 \pm 4$ & $\begin{array}{l}\text { Equivalent } \\
\text { dose }\end{array}$ & $\begin{array}{l}\text { Improvement in } 63 \% \text { of patients } \\
\text { Decrease in DAS } 28 \text { of } 0.3 \text { points }(P<0.05) \\
\text { after I month and of } 0.5 \text { points }(P<0.01) \text { over } \\
4 \text { months }\end{array}$ \\
\hline 35 & $\begin{array}{l}\text { Retrospective analysis of } 80 \text { RA } \\
\text { patients }\end{array}$ & $\begin{array}{l}\text { Gastrointestinal } \\
\text { AEs }\end{array}$ & $15.1 \pm 5.8$ & $16.5 \pm 5.2$ & $\begin{array}{l}\text { Significant decrease of DAS28, ESR, and CRP } \\
\text { levels, and pain severity (VAS) after I and } \\
3 \text { months }\end{array}$ \\
\hline 36 & $\begin{array}{l}\text { Retrospective study of I03 RA } \\
\text { patients }\end{array}$ & $\begin{array}{l}\text { Inefficacy }(n=40) \\
\text { intolerance }(n=63)\end{array}$ & 15 & 15 & $\begin{array}{l}\text { Significant improvements in DAS28 scores, } \\
\text { especially in patients who failed oral MTX } \\
\text { therapy due to intolerance }\end{array}$ \\
\hline 37 & $\begin{array}{l}\text { Retrospective study of } 78 \text { RA } \\
\text { patients }\end{array}$ & $\begin{array}{l}\text { Inefficacy }(n=38) \text {, } \\
\text { AEs }(n=40)\end{array}$ & 20 & 22 & $\begin{array}{l}\text { After } 6 \text { months, decrease in DAS } 28 \geq 1.2 \\
\text { in } 74 \% \text { of cases; "good" or better response } \\
\text { according to EULAR criteria in } 58 \% \text { of patients }\end{array}$ \\
\hline 38 & $\begin{array}{l}\text { Retrospective study of } 50 \text { RA } \\
\text { patients }\end{array}$ & $\begin{array}{l}\text { Lack of efficacy } \\
(69.6 \%), \text { AEs } \\
(28.2 \%) \text {, or both } \\
(2.2 \%)\end{array}$ & $|4.3|$ & 18.36 & $\begin{array}{l}\text { Lack of efficacy responsible for stopping } \\
\text { SC MTX in only three patients } \\
\text { The probabilities of discontinuation after I, } 2 \text {, } \\
\text { and } 3 \text { years of SC MTX treatment are expected } \\
\text { to be } 6.10 \%, 8.50 \% \text {, and } 23.20 \% \text {, respectively }\end{array}$ \\
\hline 39 & $\begin{array}{l}\text { Retrospective study of } 3 \text { I JIA } \\
\text { patients }\end{array}$ & $\begin{array}{l}\text { Insufficient/no } \\
\text { response }(n=20) \\
\text { intolerance }(n=I I)\end{array}$ & $13.8 / \mathrm{m}^{2 *}$ & $15.4 / \mathrm{m}^{2 *}$ & $\begin{array}{l}\text { After } 3 \text { months, improvement } * * \text { in } 76 \% \text { of } \\
\text { patients }\end{array}$ \\
\hline 40 & $\begin{array}{l}\text { Single-center, questionnaire-based } \\
\text { study of unselected JIA patients } \\
\text { (switch required in } 32 \text { patients) }\end{array}$ & $\begin{array}{l}\text { Intolerance }(n=20) \\
\text { reluctance to take } \\
\text { oral } \operatorname{MTX}(n=12)\end{array}$ & $12.6 / \mathrm{m}^{2}$ & $12.8 / \mathrm{m}^{2}$ & $\begin{array}{l}\text { After } 6 \text { months, no changes in the ACR score. } \\
\text { Improvement in } 12 \text { children ( } 37.5 \%) \text {, worsening } \\
\text { in other } 12(37.5 \%)\end{array}$ \\
\hline
\end{tabular}

Notes: *Mean maximum dose. **Defined as $\geq 30 \%$ improvement from baseline in three of five variables in the core set, with no more than one of the remaining variables worsening by $>30 \%$.

Abbreviations: ACR, American College of Rheumatology; AE, adverse event; CRP, C reactive protein; DAS28, 28-joint Disease Activity Score; ESR, erythrocyte sedimentation rate; EULAR, European League Against Rheumatism; JIA, juvenile idiopathic arthritis; MTX, methotrexate; RA, rheumatoid arthritis; SC, subcutaneous; VAS, visual analog scale.

gastroesophageal reflux symptoms which might have contributed to intolerance of oral MTX. ${ }^{37}$ The authors described an impressive effect of SC MTX in patients who failed to tolerate or respond to oral MTX, as the response to a 6-month SC MTX course was similar to that attainable with biological drugs in three quarters of these patients, leading to potential economic advantages.

In 30 patients who were switched from oral to SC MTX, a decrease in disease activity was associated with increased erythrocyte levels of polyglutamates $\operatorname{MTXGlu}_{5}(P=0.035)$ and MTXGlu $_{3-5}(P=0.032) \cdot{ }^{24}$ Likewise, Dervieux et al showed a significant reduction in disease activity in association with a selective accumulation of long-chain MTX polyglutamates in 10 RA patients switched from oral to parenteral MTX. ${ }^{23}$

\section{Tolerability data}

A synopsis of the most relevant tolerability outcomes observed in clinical studies involving patients with RA and JIA is shown in Table 4. ${ }^{27-31,33,35,38-45}$
The prospective, randomized, controlled trial carried out by Braun et al demonstrated that SC administration of MTX was significantly more effective than oral administration at the same dosage, without inducing any relevant increase in side effects. ${ }^{27}$ However, more patients in the SC MTX group $(9.3 \%)$ than in the oral MTX group (4.3\%) prematurely discontinued the study because of adverse events (AEs). The frequencies of moderate-to-severe AEs registered at $\geq 3 \%$ incidence were higher in patients treated with oral MTX. Even the gastrointestinal AEs were comparable between the two formulations. Diarrhea was reported more frequently in patients who received oral MTX and loss of appetite was reported in those belonging to the SC MTX group.

In spite of the greater systemic MTX exposure with SC dosing particularly at dosages $\geq 15 \mathrm{mg}$ /week in the pharmacokinetic analysis performed by Schiff et al, the authors likewise revealed no increase in AEs with SC MTX. ${ }^{13}$

According to Rutkowska-Sak et al, ${ }^{45} \mathrm{SC}$ administration of MTX has generally been associated with a significant 
Table 4 Tolerability data regarding oral MTX and SC MTX in patients with RA and JIA

\begin{tabular}{|c|c|c|}
\hline References & Patients treated with MTX and study details & Summary of the tolerability data \\
\hline \multicolumn{3}{|c|}{ SC MTX vs oral MTX } \\
\hline 27 & 384 patients with RA* & $\begin{array}{l}\text { Similar rate of total AEs and GI AEs. Diarrhea was more } \\
\text { common with oral MTX ( } 6.9 \% \text { vs } 2.6 \%) \text { and loss of appetite } \\
\text { was more common with SC MTX ( } 7.3 \% \text { vs } 3.2 \%) \text {. Withdrawal } \\
\text { due to AEs was more frequent with SC MTX }\end{array}$ \\
\hline 28 & 92 patients with RA* & $\begin{array}{l}\text { AEs less frequent with SC MTX, eg, nausea ( } 37 \% \text { vs } 63 \%) \text {, } \\
\text { vomiting (II\% vs } 30 \%) \text {, dyspepsia ( } 29 \% \text { vs } 48 \%) \text {, dizziness } \\
\text { ( } 41 \% \text { vs } 52 \%) \text {, and alopecia ( } 72 \% \text { vs } 85 \%)\end{array}$ \\
\hline 41 & $\begin{array}{l}\text { Online survey in RA patients } \\
\text { SC MTX }(n=49) \text {, oral MTX }(n=\mid 15)\end{array}$ & $\begin{array}{l}\text { Prevalence of diarrhea was lower among patients receiving } \\
\text { SC MTX. Nausea, mental fog, and hair loss were more } \\
\text { frequent with SC MTX }\end{array}$ \\
\hline 29 & 666 patients with early RA* & No difference in failure due to toxicity \\
\hline 42 & $\begin{array}{l}\text { Questionnaire-based study in } 106 \text { unselected } \\
\text { patients with inflammatory arthritis, } 57 \text { adults ( } 33 \% \\
\text { on SC MTX) and } 49 \text { adolescents ( } 49 \% \text { on SC MTX) }\end{array}$ & $\begin{array}{l}\text { Nausea reported in } 77 \% \text { of patients on SC MTX vs } 37 \% \text { in the } \\
\text { oral group }(P<0.000 \mathrm{I}) \\
\text { Risk of nausea was significantly associated with the use of } \\
\text { SC MTX (OR } 4.49,95 \% \mathrm{Cl} \text { I.7I-II.79) }\end{array}$ \\
\hline 30 & 4II patients with JIA* & $\begin{array}{l}\text { At least one AE in } 21 \% \text { of cases with oral MTX and } 27 \% \\
\text { with SC MTX (no statistical significance). Significantly more } \\
\text { discontinuations due to AEs with SC MTX (II\% vs } 5 \% \text {; } \\
\text { type of AE not specified) }\end{array}$ \\
\hline 31 & 55 patients with JIA* & $\begin{array}{l}\text { Trend toward increased odds for intolerance with SC MTX } \\
\text { (OR 2.4; } 95 \% \mathrm{Cl} 0.56-10.65, P=0.236 \text { ) }\end{array}$ \\
\hline 43 & $\begin{array}{l}\text { Cross-sectional study of } 179 \text { JIA patients. } \\
\text { Exclusive treatment with oral MTX in } 95 \text { patients } \\
\text { and with SC MTX in } 46 \text { (similar median dose of } \\
\text { I1.8-11.6 mg/m²/week) }\end{array}$ & $\begin{array}{l}\text { MTX intolerance was more frequent in patients with exclusive } \\
\text { use of SC MTX (aOR } 3.37,95 \% \mathrm{CI} 1.19-10.0) \text {. Significant } \\
\text { differences were due to behavioral complaints with no } \\
\text { difference in prevalence of nausea or vomiting between groups }\end{array}$ \\
\hline \multicolumn{3}{|c|}{ Switch from oral MTX to SC MTX } \\
\hline 33 & I96 RA patients* & $\begin{array}{l}\text { After } 2 \text { years, drug discontinuation due to AEs was in } 22.2 \% \text { of } \\
\text { patients who did not tolerate oral MTX }\end{array}$ \\
\hline 35 & 80 RA patients switched because of GI AEs* & $\begin{array}{l}\text { Significantly less patients with GI AEs in the first }(n=30) \text { and } \\
\text { third month }(n=27) \text { visits }\end{array}$ \\
\hline 38 & 50 RA patients* & Discontinuation of SC MTX because of AEs in six patients \\
\hline 44 & $\begin{array}{l}\text { Retrospective postal survey exploring GI AEs in } \\
39 \text { patients from dermatology/rheumatology centers; } \\
\text { significant increase in weekly dose with change from } \\
\text { oral MTX }(14.2 \pm 5.1 \mathrm{mg}) \text { to SC MTX (16.2 } \pm 5.0 \mathrm{mg})\end{array}$ & $\begin{array}{l}\text { Significant reductions were observed in VAS related to } \\
\text { frequency and intensity of nausea and frequency of discomfort. } \\
\text { Frequency of vomiting was not significantly reduced }\end{array}$ \\
\hline 39 & 3I JIA patients (switching in II due to nausea)* & $\begin{array}{l}\text { Disappearance of nausea in nine patients (less severe in the } \\
\text { other two who continued MTX therapy) }\end{array}$ \\
\hline 40 & 32 patients with JIA (20 with intolerance)* & $\begin{array}{l}\text { Over } 6 \text { months, symptoms of drug intolerance (mostly } \\
\text { Gl symptoms) in three children }\end{array}$ \\
\hline 45 & $\begin{array}{l}\text { Survey in } 70 \text { RA patients initially treated with oral } \\
\text { MTX ( } 7.5 \text { or } 15 \mathrm{mg} / \text { week) and then switched to the } \\
\text { same dose of SC MTX because of GI AEs }\end{array}$ & More intense GI AEs with oral MTX (in relation to MTX dose) \\
\hline
\end{tabular}

Note: *For details regarding study design, patients, and MTX dose, see Tables 2 and 3.

Abbreviations: AE, adverse event; aOR, adjusted odds ratio; GI, gastrointestinal; JIA, juvenile idiopathic arthritis; MTX, methotrexate; OR, odds ratio; RA, rheumatoid arthritis; SC, subcutaneous; VAS, visual analog scale.

reduction in gastrointestinal side effects compared with equivalent oral administration.

A single-dose pharmacokinetic study in healthy subjects detected differences in the safety profile with more gastrointestinal complaints after oral administration than SC dosing $(15 \%$ vs $28 \%){ }^{15}$

A survey used a questionnaire that was completed by a physician and administered to 70 RA MTX-treated patients in order to explore the gastrointestinal tolerability associated with different doses and route of administration. ${ }^{45}$ Such patients initially received oral MTX (7.5 or $15 \mathrm{mg} /$ week) and then were switched to SC MTX because of gastrointestinal side effects, thus receiving the same dose of the drug. Oral MTX caused more intense gastroenteric symptoms, and a correlation between dose of oral MTX and severity of side effects was detected. The article reported the type and frequency of gastrointestinal AEs. In particular, patients receiving $15 \mathrm{mg}$ MTX orally were susceptible to more 
intense vomiting. The patients treated with SC MTX had less intense side effects such as nausea and abdominal pain, whereas none of them had vomiting or diarrhea. Intensity of loss of appetite showed no difference between $15 \mathrm{mg}$ oral and SC MTX and was instead higher with $7.5 \mathrm{mg}$ SC MTX than $7.5 \mathrm{mg}$ oral MTX.

A meta-analysis in RA patients showed that SC MTX can significantly reduce the occurrence of nausea (OR 0.53 ; 95\% CI 0.28-0.97) and diarrhea (OR 0.43; 95\% CI 0.20-0.95) in comparison with oral MTX, while differences in the development of headache, vomiting, and dyspepsia were not detected..$^{18}$ On the other hand, some studies have surprisingly found the prevalence of MTX-induced nausea to be greater in patients receiving parenteral MTX compared with those who took MTX orally.

In an online survey among RA patients who were members of a large arthritis patient community, 382 respondents were naïve for a biologic agent $(n=218), \operatorname{SC} \operatorname{MTX}(n=49)$, or oral $\operatorname{MTX}(n=115)$ in the last 12 months. ${ }^{41}$ The patient-reported prevalence of diarrhea was lower among patients treated with SC MTX than among those on oral MTX, while nausea was more frequently reported with SC MTX. The proportions of patients experiencing mental fog and hair loss were higher in patients treated with SC MTX, and this finding was believed to be due to the high drug exposure resulting from $\mathrm{SC}$ administration. The frequency and the intensity of pain at the site of injection were significantly lower with SC MTX than with etanercept and adalimumab.

Patil et al explored in depth the nausea and vomiting domains by means of a survey of 49 adolescents and 57 adults with inflammatory arthritis who were using either oral or SC MTX as monotherapy for at least 3 months. ${ }^{42}$ Seventythree percent of adolescents reported nausea compared with $35 \%$ of adults $(P<0.001)$. Multiple logistic regression analysis showed that the risk of nausea was significantly associated with being adolescent patients compared with adult patients (OR 6.31, 95\% CI 2.38-16.75, $P=0.0002$ ), as well as with use of SC MTX (OR 4.49, 95\% CI 1.71-11.79, $P=0.002$ ) and duration of MTX therapy (OR 3.86, 95\% CI 1.00-14.89, $P=0.05)$. Moreover, adolescent patients were estimated to have over six times higher odds of vomiting compared with adult patients.

A high prevalence of MTX-induced gastrointestinal intolerance in JIA has recently been reported by Bulatović et al. ${ }^{46}$ MTX intolerance in younger patients has been related to the frequent occurrence of anticipatory and associative complaints in adolescents. Anticipatory nausea is a known psychological adverse effect of MTX that develops through classical conditioning. In the aforementioned survey of Patil et al, $41 \%$ of adolescents and $30 \%$ of adults experienced anticipatory nausea. ${ }^{42}$

Results obtained from studies in children or adolescents are, therefore, likely to deserve cautious interpretation taking into account the age-related peculiarities seen in this category.

A survey among children and young people with JIA in the UK has revealed that psychosocial health-related quality of life was poorer in patients taking MTX by SC rather than oral route. ${ }^{47}$

\section{Pharmacoeconomic considerations in rheumatic diseases}

Some retrospective studies have documented relatively high persistence rates of SC MTX treatment, ${ }^{33,38}$ and this, therefore, may minimize or postpone the need to initiate expensive biological therapy. However, there are controversial data from the real-life experience.

For instance, in large cohorts of RA patients from USA administrative databases, the effects of the following three different strategies were examined: increasing the oral MTX dose; adding other traditional DMARDs to oral MTX; or switching from oral MTX to SC MTX. ${ }^{48}$ There was no significant difference in the time to initiation of biologic agents between the three treatment strategies. In such cohorts, however, SC MTX therapy seemed to be underutilized and was found to be switched from oral MTX in only 3\%-4\% of RA patients.

The economic impact of SC MTX or a biologic over a 12-month period was assessed using a decision-based model to define the management of a hypothetical UK population of RA patients who were eligible for biologic therapy after failure of oral treatment with MTX because of intolerance and/or inefficacy. ${ }^{49}$ Published data on the continuation rates of SC MTX and biologics were utilized to compare the costs of the two treatment options. The economic model was created on the basis of current National Institute for Health and Clinical Excellence (NICE) guidance and used a cost-minimization methodology from a UK National Health Service (NHS) perspective, taking into account the cost of all drugs and resources. The routine use of SC MTX following oral MTX failure was shown to have the potential to give considerable savings to the NHS. Sensitivity analyses confirmed the robustness of such results. It was, therefore, suggested that patients on oral MTX should undergo a subsequent switch to SC MTX in the case of intolerance or ineffectiveness, before introducing a biologic agent. 
A recent study has examined the 5-year health-care costs of different treatment strategies for patients with RA who initiate oral MTX in the USA. For this purpose, the study population was distinguished into four treatment cohorts, consisting in patients who 1) continued to use oral MTX, 2) switched to SC MTX, 3) switched to SC MTX and then added or switched to a biologic therapy, and 4) added or switched to a biologic therapy. ${ }^{50}$ The costs for pharmaceuticals, office visits, hospitalizations, and emergency department visits were calculated. Results showed that there were lower costs in patients who switched to SC MTX than in those who received only oral MTX before using biologics.

\section{Psoriatic disease: clinical and pharmacoeconomic aspects}

There are very few data concerning SC MTX treatment in psoriatic disease. Moreover, no study has compared SC and oral routes of administration for the management of psoriasis.

Based on the results of a systematic review of MTX in psoriasis and expert opinion, ${ }^{51}$ the initiation of treatment by oral administration is generally preferred. If the efficacy is not sufficient or gastrointestinal tolerance is poor, the use of SC/intramuscular route at the same dosage is suggested. However, if there is a risk of poor compliance, it has been proposed that treatment can be initiated parenterally.

Nevertheless, it is probable that many dermatologists are not yet familiar with the SC route when prescribing MTX.

A survey examining practice preferences of MTX use among Canadian dermatologists and rheumatologists showed that the latter were more likely than dermatologists to switch to a parenteral route and to use SC injections. ${ }^{52}$ The majority of dermatologists (97\%) and rheumatologists $(80 \%)$ in everyday practice reported the prescription of oral MTX as the initial treatment. Fewer dermatologists declared to perform a subsequent switch to parenteral MTX (49\% vs 96\% of rheumatologists). SC route was chosen as the modality of MTX parental administration by $63 \%$ of dermatologists and $98 \%$ of rheumatologists.

A questionnaire was completed by 39 Iranian dermatologists who were experts in psoriasis to obtain information on the use of MTX in their clinical practice..$^{53}$ Overall, there was a low level of agreement regarding several aspects of MTX dosing and treatment monitoring. Among respondents, $71.8 \%$ reported to prescribe MTX as oral route and $28.2 \%$ as intramuscular administration, while none chose the SC injection as the usual route of administration.

The most important publication concerning SC MTX in psoriasis refers to the METOP study, an investigator-initiated, multicenter, randomized, double-blind, placebo-controlled, Phase III trial performed at 16 sites in Germany, France, the Netherlands, and the UK. ${ }^{54}$ Eligible participants were MTX-naïve adults with a diagnosis of plaque-type psoriasis for at least 6 months and suffering from moderate-to-severe disease. A total of 120 patients were randomized according to a 3:1 ratio to receive SC MTX $(n=91)$ or placebo $(n=29)$. The weekly dose of MTX was initially $17.5 \mathrm{mg}$ with possible escalation to $22.5 \mathrm{mg}$ after 8 weeks if patients did not achieve at least a 50\% reduction in PASI (PASI50).

The study design consisted of an initial 16-week doubleblind phase. From week 16 onward, MTX was administered on an open-label basis to all patients. From week 16 to week 52, patients initially on MTX treatment continued the same dose unless they did not achieve PASI75 with $17.5 \mathrm{mg} /$ week after 24 weeks, and then dose escalation to $22.5 \mathrm{mg}$ was permitted in these cases, while those already treated with a weekly dose of $22.5 \mathrm{mg}$ who were not PASI50 responders at week 24 were withdrawn from the study. Patients belonging to the placebo group were switched to MTX $17.5 \mathrm{mg} /$ week at week 16, with possible change to $22.5 \mathrm{mg}$ at week 24, if PASI50 was not reached.

At week 16, a PASI75 response (primary efficacy end point) was observed in $41 \%$ of patients in the MTX group compared with $10 \%$ in the placebo group (relative risk 3.93 , 95\% CI 1.31-11.81; $P=0.0026$ ). Response rates increased with continuous MTX treatment. A nonresponder imputation analysis of the modified intent-to-treat population showed that PASI75 response rates at week 52 were $45 \%$ in the MTX-MTX group and 34\% in the placebo-MTX group. At week 52, PASI improvement $\geq 90 \%$ was seen in almost $28 \%$ of patients in each group, and a static physicians' global assessment score of 0 or 1 (corresponding to a "clear" or "almost clear" disease) was recorded in nearly $40 \%$ of patients in both groups. Response of plaque psoriasis was accompanied by significant improvement of concomitant nail psoriasis and health-related quality of life measured by the Dermatology Life Quality Index.

The dropout rate over 52 weeks in patients treated with SC MTX in the METOP study was 39\% $(n=35 / 91)$, with 8 patients discontinuing because of poor efficacy and 19 due to AEs. During the placebo-controlled study phase, gastrointestinal AEs (especially nausea or vomiting) and increases in hepatic enzymes were more common in the MTX group than in the placebo group. Gastrointestinal AEs were usually mild or moderate and led to permanent discontinuation of study drug in 3\% of patients who received MTX during the entire study period. Over 52 weeks, elevation of hepatic enzymes 
was reported in $23 \%$ of patients started on MTX, with $12 \%$ permanently discontinuing treatment.

A biopsy substudy found that the clinical response to SC MTX was correlated to a marked decrease in numbers of skininfiltrating CD3-positive T cells and CD11c-positive dendritic cells and to downregulation in the cutaneous expression of specific $\mathrm{T}$ helper cell type 1 and type 17 cytokines. $^{54}$

A retrospective study has evaluated 85 patients who were prescribed SC MTX for chronic plaque psoriasis in three dermatology centers in the UK. ${ }^{55}$ The median number of systemic agents used prior to SC MTX was three, with oral MTX previously used in 82 subjects and subsequently stopped because of ineffectiveness or partial response $(n=24)$ or AEs (nausea $n=43$, headache $n=3$, increased liver enzymes $n=2$, and lethargy $n=2$ ). The mean weekly dose of SC MTX was $18.5 \mathrm{mg}$ (range $7.5-30 \mathrm{mg}$ ), and treatment duration varied from 2 months to 67 months (mean 14 months). Clinical response was obtained in 59 patients, described as "clear" or "almost clear" in 20 of them. SC MTX was stopped in 10 patients because of inefficacy $(n=5)$, nausea $(n=4)$, and injection site reaction $(n=1)$.

Another multicenter retrospective study showed a high adherence rate after 6 months of treatment with SC MTX in 103 patients with plaque-type psoriasis, most of whom previously treated with other systemic nonbiologic therapies, including oral MTX. ${ }^{56}$ As regards efficacy, the same study showed that $47 \%$ of patients achieved PASI75 at 6 months, and $87 \%$ of patients who switched from oral MTX due to inefficacy were still on treatment after 6 months of SC MTX, with a PASI 75 response observed in $38 \%$ of such patients.

A pharmacoeconomic analysis was carried out in Spain starting from the premises of superior efficacy of SC MTX in RA. ${ }^{3}$ It has recognized that the additional cost related to the use of the SC route would be counterbalanced by better effectiveness. Moreover, the results of an incremental costeffectiveness analysis of SC MTX and several alternatives based on data from comparative clinical trials suggested that SC MTX has a higher incremental cost-effectiveness ratio to ciclosporin, adalimumab, and infliximab in the treatment of moderate-to-severe psoriasis. ${ }^{3}$

\section{Discussion}

Current evidence indicates that SC administration of MTX is characterized by linear and predictable pharmacokinetics resulting in higher bioavailability as compared with oral MTX, especially with weekly doses of $\geq 15 \mathrm{mg}$. ${ }^{10,12-17}$ These findings have been found to be paralleled by an improved pharmacodynamic profile related to an enhanced intracellular polyglutamation. ${ }^{23,24}$
Various clinical experiences, mostly concerning RA patients, give evidence that SC MTX is more effective than oral MTX and may induce significant benefit even in patients in whom oral MTX proved to be inadequate. The increased efficacy of SC MTX resulting from higher drug exposure compared with oral MTX has been associated with a similar safety profile and in various reports even with a lower frequency of gastrointestinal complaints.

It should be stressed that the study design of many studies does not allow a direct comparison of the efficacy and tolerability profiles between oral and SC formulations of MTX. Moreover, the majority of comparative studies were open labeled, and most of the studies examining patients who were changed from oral to SC MTX were retrospective.

The prospective, randomized, double-blind, controlled trial carried out by Braun et al demonstrated that SC administration of MTX was significantly more effective than oral administration at the same dosage, without any relevant increase in side effects. ${ }^{27}$ The authors observed statistically significant differences in the ACR20 and ACR70 response in favor of SC MTX, with even better ACR20 response rates among patients with a disease duration $\geq 12$ months. The gastrointestinal AEs were found to be similar between the two formulations.

The cumulative evidence on RA has been summarized in a recent meta-analysis the outcomes of which showed that SC MTX can significantly improve the ACR20 and ACR70 responses and the pain severity, and reduce the occurrence of nausea and diarrhea compared with oral MTX. ${ }^{18}$ However, the two formulations were not significantly different in terms of occurrence of headache, vomiting, and dyspepsia, as well as risk of treatment failure.

Preliminary data suggest the possibility of high persistence rates and optimal adherence with SC MTX. ${ }^{33,38}$ This may minimize or delay the need to start more expensive alternative therapies, having a considerable economic impact.

Therefore, in RA patients refractory to oral MTX, switching to parenteral administration has been recommended as a useful strategy before introducing other therapies. ${ }^{57,58}$

There are only a limited number of data on the efficacy and tolerability of SC MTX in JIA, which appear to be more controversial than those available for RA, and even fewer in psoriatic disease.

\section{Conclusion}

SC MTX appears an interesting and valid therapeutic option for inflammatory arthritis and psoriatic disease. Also, SC administration may overcome some limitations of oral MTX therapy. It entails optimization of MTX treatment, improving 
outcomes and compliance with relevant pharmacoeconomic implications.

However, large randomized trials with low risk of bias due to the study design and methodology are required to draw definite conclusions.

\section{Acknowledgment}

The authors thank Mundipharma Pharmaceuticals Srl, Italy, for the editorial support.

\section{Disclosure}

GAV served as a speaker and/or advisory board member for Novartis, AbbVie, MSD, Pfizer, and LEO Pharma. NC served as a scientific consultant and/or speaker for Novartis, AbbVie, LEO Pharma, MSD, and Pfizer. FI received personal fees from Actelion, Celgene, Janssen, Pfizer, AbbVie, UCB, and MSD outside the submitted work. The authors report no other conflicts of interest in this work.

\section{References}

1. Smolen JS, Landewé R, Bijlsma J, et al. EULAR recommendations for the management of rheumatoid arthritis with synthetic and biological disease-modifying antirheumatic drugs: 2016 update. Ann Rheum Dis. 2017;76(6):960-977.

2. Pincus T, Bergman MJ, Yazici Y. Limitations of clinical trials in chronic diseases: is the efficacy of methotrexate (MTX) underestimated in polyarticular psoriatic arthritis on the basis of limitations of clinical trials more than on limitations of MTX, as was seen in rheumatoid arthritis? Clin Exp Rheumatol. 2015;33(5 Suppl 93):S82-S93.

3. Puig L. Methotrexate: new therapeutic approaches. Actas Dermosifiliogr. 2014;105(6):583-589.

4. Zweegers J, Otero ME, van den Reek JM, et al. Effectiveness of biologic and conventional systemic therapies in adults with chronic plaque psoriasis in daily practice: a systematic review. Acta Derm Venereol. 2016; 96(4):453-458.

5. Lima A, Sousa H, Monteiro J, Azevedo R, Medeiros R, Seabra V. Genetic polymorphisms in low-dose methotrexate transporters: current relevance as methotrexate therapeutic outcome biomarkers. Pharmacogenomics. 2014;15(12):1611-1635.

6. Moya P, Corominas H, Salazar J, Díaz-Torné C. A step forward in methotrexate pharmacogenetics. Reumatol Clin. 2017;13(5):305.

7. Sharma P, Scott DG. Optimizing methotrexate treatment in rheumatoid arthritis: the case for subcutaneous methotrexate prior to biologics. Drugs. 2015;75(17):1953-1956.

8. Bello AE, Perkins EL, Jay R, Efthimiou P. Recommendations for optimizing methotrexate treatment for patients with rheumatoid arthritis Open Access Rheumatol. 2017;9:67-79.

9. Yadlapati S, Efthimiou P. Inadequate response or intolerability to oral methotrexate: Is it optimal to switch to subcutaneous methotrexate prior to considering therapy with biologics? Rheumatol Int. 2016;36(5): 627-633.

10. Jundt JW, Browne BA, Fiocco GP, Steele AD, Mock D. A comparison of low dose methotrexate bioavailability: oral solution, oral tablet, subcutaneous and intramuscular dosing. J Rheumatol. 1993;20(11):1845-1849.

11. Brooks PJ, Spruill WJ, Parish RC, Birchmore DA. Pharmacokinetics of methotrexate administered by intramuscular and subcutaneous injections in patients with rheumatoid arthritis. Arthritis Rheum. 1990;33(1):91-94.

12. Hoekstra M, Haagsma C, Neef C, Proost J, Knuif A, van de Laar M. Bioavailability of higher dose methotrexate comparing oral and subcutaneous administration in patients with rheumatoid arthritis. J Rheumatol. 2004;31(4):645-648.
13. Schiff MH, Jaffe JS, Freundlich B. Head-to-head, randomized, crossover study of oral vs subcutaneous methotrexate in patients with rheumatoid arthritis: drug-exposure limitations of oral methotrexate at doses $\geq 15 \mathrm{mg}$ may be overcome with subcutaneous administration. Ann Rheum Dis. 2014;73(8):1549-1551.

14. Tuková J, Chládek J, Nemcová D, Chládková J, Dolezalová P. Methotrexate bioavailability after oral and subcutaneous administration in children with juvenile idiopathic arthritis. Clin Exp Rheumatol. 2009;27(6):1047-1053.

15. Pichlmeier U, Heuer KU. Subcutaneous administration of methotrexate with a prefilled autoinjector pen results in a higher relative bioavailability compared with oral administration of methotrexate. Clin Exp Rheumatol. 2014;32(4):563-571.

16. Kurnik D, Loebstein R, Fishbein E, et al. Bioavailability of oral vs subcutaneous low-dose methotrexate in patients with Crohn's disease. Aliment Pharmacol Ther. 2003;18(1):57-63.

17. Wilson A, Patel V, Chande N, et al. Pharmacokinetic profiles for oral and subcutaneous methotrexate in patients with Crohn's disease. Aliment Pharmacol Ther. 2013;37(3):340-345.

18. Li D, Yang Z, Kang P, Xie X. Subcutaneous administration of methotrexate at high doses makes a better performance in the treatment of rheumatoid arthritis compared with oral administration of methotrexate: a systematic review and meta-analysis. Semin Arthritis Rheum. 2016; 45(6):656-662.

19. Schiff MH, Sadowski P. Oral to subcutaneous methotrexate doseconversion strategy in the treatment of rheumatoid arthritis. Rheumatol Int. 2017;37(2):213-218.

20. Quist SR, Quist J, Birkenmaier J, Stauch T, Gollnick HP. Pharmacokinetic profile of methotrexate in psoriatic skin via the oral or subcutaneous route using dermal microdialysis showing higher methotrexate bioavailability in psoriasis plaques than in non-lesional skin. J Eur Acad Dermatol Venereol. 2016;30(9):1537-1543.

21. Cronstein BN. Low-dose methotrexate: a mainstay in the treatment of rheumatoid arthritis. Pharmacol Rev. 2005;57(2):163-172.

22. Mohamed HJ, Sorich MJ, Kowalski SM, et al. The role and utility of measuring red blood cell methotrexate polyglutamate concentrations in inflammatory arthropathies-a systematic review. Eur J Clin Pharmacol. 2015;71(4):411-423.

23. Dervieux T, Zablocki R, Kremer J. Red blood cell methotrexate polyglutamates emerge as a function of dosage intensity and route of administration during pulse methotrexate therapy in rheumatoid arthritis. Rheumatology (Oxford). 2010;49(12):2337-2345.

24. Stamp LK, Barclay ML, O'Donnell JL, et al. Effects of changing from oral to subcutaneous methotrexate on red blood cell methotrexate polyglutamate concentrations and disease activity in patients with rheumatoid arthritis. J Rheumatol. 2011;38(12):2540-2547.

25. Becker ML, van Haandel L, Gaedigk R, et al. Analysis of intracellular methotrexate polyglutamates in patients with juvenile idiopathic arthritis: effect of route of administration on variability in intracellular methotrexate polyglutamate concentrations. Arthritis Rheum. 2010; 62(6): 1803-1812.

26. O'Connor A, Thorne C, Kang H, Tin D, Pope JE. The rapid kinetics of optimal treatment with subcutaneous methotrexate in early inflammatory arthritis: an observational study. BMC Musculoskelet Disord. 2016;17(1):364.

27. Braun J, Kästner P, Flaxenberg P, et al; MC-MTX.6/RH Study Group. Comparison of the clinical efficacy and safety of subcutaneous vs oral administration of methotrexate in patients with active rheumatoid arthritis: results of a six-month, multicenter, randomized, double-blind, controlled, phase IV trial. Arthritis Rheum. 2008;58(1): 73-81.

28. Islam MS, Haq SA, Islam MN, et al. Comparative efficacy of subcutaneous vs oral methotrexate in active rheumatoid arthritis. Mymensingh Med J. 2013;22(3):483-488.

29. Hazlewood GS, Thorne JC, Pope JE, et al; CATCH Investigators. The comparative effectiveness of oral vs subcutaneous methotrexate for the treatment of early rheumatoid arthritis. Ann Rheum Dis. 2016;75(6): $1003-1008$ 
30. Klein A, Kaul I, Foeldvari I, Ganser G, Urban A, Horneff G. Efficacy and safety of oral and parenteral methotrexate therapy in children with juvenile idiopathic arthritis: an observational study with patients from the German Methotrexate Registry. Arthritis Care Res (Hoboken). 2012;64(9):1349-1356.

31. Fráňová J, Fingerhutová Š, Kobrová K, et al. Methotrexate efficacy, but not its intolerance, is associated with the dose and route of administration. Pediatr Rheumatol Online J. 2016;14(1):36.

32. Rozin A, Schapira D, Balbir-Gurman A, et al. Relapse of rheumatoid arthritis after substitution of oral for parenteral administration of methotrexate. Ann Rheum Dis. 2002;61(8):756-757.

33. Scott DG, Claydon P, Ellis C. Retrospective evaluation of continuation rates following a switch to subcutaneous methotrexate in rheumatoid arthritis patients failing to respond to or tolerate oral methotrexate: the MENTOR study. Scand J Rheumatol. 2014;43(6): $470-476$.

34. Bakker MF, Jacobs JW, Welsing PM, et al; Utrecht Arthritis Cohort Study Group. Are switches from oral to subcutaneous methotrexate or addition of ciclosporin to methotrexate useful steps in a tight control treatment strategy for rheumatoid arthritis? A post hoc analysis of the CAMERA study. Ann Rheum Dis. 2010;69(10):1849-1852.

35. Borman P, Demir G, Kaygısız F, Okumuş M. LETTER TO THE EDITOR Subcutaneous (SC) methotrexate (MTX) is better and welltolerable than oral MTX in rheumatoid arthritis patients, switched from oral to SC administration due to gastrointestinal side effects. Open Rheumatol J. 2014;8:18-19.

36. Hameed B, Jones H. Subcutaneous methotrexate is well tolerated and superior to oral methotrexate in the treatment of rheumatoid arthritis. Int J Rheum Dis. 2010;13(4):e83-e84.

37. Mainman H, McClaren E, Heycock C, Saravanan V, Hamilton J, Kelly C. When should we use parenteral methotrexate? Clin Rheumatol. 2010; 29(10):1093-1098.

38. Branco JC, Barcelos A, de Araújo FP, et al. Utilization of subcutaneous methotrexate in rheumatoid arthritis patients after failure or intolerance to oral methotrexate: a multicenter cohort study. Adv Ther. 2016; 33(1):46-57.

39. Alsufyani K, Ortiz-Alvarez O, Cabral DA, Tucker LB, Petty RE, Malleson PN. The role of subcutaneous administration of methotrexate in children with juvenile idiopathic arthritis who have failed oral methotrexate. J Rheumatol. 2004;31(1):179-182.

40. Żuber Z, Turowska-Heydel D, Sobczyk M, et al. Methotrexate efficacy and tolerability after switching from oral to subcutaneous route of administration in juvenile idiopathic arthritis. Reumatologia. 2016; 54(1):19-23.

41. Curtis JR, Xie F, Mackey D, et al. Patient's experience with subcutaneous and oral methotrexate for the treatment of rheumatoid arthritis. BMC Musculoskelet Disord. 2016;17(1):405.

42. Patil P, Parker RA, Rawcliffe C, et al. Methotrexate-induced nausea and vomiting in adolescent and young adult patients. Clin Rheumatol. 2014;33(3):403-407.

43. van Dijkhuizen EH, Pouw JN, Scheuern A, et al. Methotrexate intolerance in oral and subcutaneous administration in patients with juvenile idiopathic arthritis: a cross-sectional, observational study. Clin Exp Rheumatol. 2016;34(1):148-154.
44. Kromann CB, Lage-Hansen PR, Koefoed M, Jemec GB. Does switching from oral to subcutaneous administration of methotrexate influence on patient reported gastro-intestinal adverse effects? J Dermatolog Treat. 2015;26(2):188-190.

45. Rutkowska-Sak L, Rell-Bakalarska M, Lisowska B. Oral vs subcutaneous low-dose methotrexate treatment in reducing gastrointestinal side effects. Reumatologia. 2009;47:207-211.

46. Bulatović M, Heijstek MW, Verkaaik M, et al. High prevalence of methotrexate intolerance in juvenile idiopathic arthritis: development and validation of a methotrexate intolerance severity score. Arthritis Rheum. 2011;63(7):2007-2013.

47. Mulligan K, Wedderburn LR, Newman S. The experience of taking methotrexate for juvenile idiopathic arthritis: results of a cross-sectional survey with children and young people. Pediatr Rheumatol Online J. 2015;13:58.

48. Curtis JR, Zhang J, Xie F, Beukelman T, et al. Use of oral and subcutaneous methotrexate in rheumatoid arthritis patients in the United States. Arthritis Care Res (Hoboken). 2014;66:1604-1611.

49. Fitzpatrick R, Scott DG, Keary I. Cost-minimisation analysis of subcutaneous methotrexate vs biologic therapy for the treatment of patients with rheumatoid arthritis who have had an insufficient response or intolerance to oral methotrexate. Clin Rheumatol. 2013;32:1605-1612.

50. Lee J, Pelkey R, Gubitosa J, Henrick MF, Ganz ML. Comparing healthcare costs associated with oral and subcutaneous methotrexate or biologic therapy for rheumatoid arthritis in the United States. Am Health Drug Benefits. 2017;10(1):42-49.

51. Montaudié H, Sbidian E, Paul C, et al. Methotrexate in psoriasis: a systematic review of treatment modalities, incidence, risk factors and monitoring of liver toxicity. J Eur Acad Dermatol Venereol. 2011; 25(Suppl 2):12-18.

52. Dupuis EC, Bhole VM, Dutz JP. Differing patterns of methotrexate use for psoriatic disease among dermatologists and rheumatologists. $\mathrm{Br} J$ Dermatol. 2012;167(2):448-450.

53. Zargari O, Hejazi S, Shahidi-Dadras M, et al. Considerable variation among Iranian dermatologists in the dosing and monitoring of methotrexate for treating psoriasis. Int J Dermatol. 2014;53(3):385-389.

54. Warren RB, Mrowietz U, von Kiedrowski R, et al. An intensified dosing schedule of subcutaneous methotrexate in patients with moderate to severe plaque-type psoriasis (METOP): a 52 week, multicentre, randomized, double-blind, placebo-controlled, phase 3 trial. Lancet. 2017; 389(10068):528-537.

55. Yesudian PD, Leman J, Balasubramaniam P, et al. Effectiveness of subcutaneous methotrexate in chronic plaque psoriasis. J Drugs Dermatol. 2016;15(3):345-349.

56. Vidal D, Salleras M, Romaní J, et al. Adherence of self-administered subcutaneous methotrexate in patients with chronic plaque-type psoriasis. J Eur Acad Dermatol Venereol. 2016;30(11):e131-e132.

57. Bianchi G, Caporali R, Todoerti M, Mattana P. Methotrexate and rheumatoid arthritis: Current evidence regarding subcutaneous vs oral routes of administration. Adv Ther. 2016;33(3):369-378.

58. Todoerti M, Maglione W, Bernero E, et al. Systematic review of 2008-2012 literature and update of recommendations for the use of methotrexate in rheumatic diseases, with a focus on rheumatoid arthritis. Reumatismo. 2013;65(5):207-218.
Therapeutics and Clinical Risk Management

\section{Publish your work in this journal}

Therapeutics and Clinical Risk Management is an international, peerreviewed journal of clinical therapeutics and risk management, focusing on concise rapid reporting of clinical studies in all therapeutic areas, outcomes, safety, and programs for the effective, safe, and sustained use of medicines. This journal is indexed on PubMed Central, CAS,

\section{Dovepress}

EMBase, Scopus and the Elsevier Bibliographic databases. The manuscript management system is completely online and includes a very quick and fair peer-review system, which is all easy to use. Visit http://www.dovepress.com/testimonials.php to read real quotes from published authors. 